\title{
Incorporating a Digital Serious Game into Real-life Distance Learning Practices via Educational Scenarios
}

\author{
Klio Stamou, Helena Koumentakou, Yorghos Voutos, and Phivos Mylonas
}

\begin{abstract}
In recent years and after continuous training of educators, the design of flexible educational scenarios is gradually evolving and being integrated into the teaching practice, which is related to the proposed ways of implementing pre-selected modules from the curriculum of a subject and can be applied to distance learning. In this context and during the development of the "BYRON" and "MON REPO" projects, educational scenarios were designed and implemented in practice. These are based on the serious games design principles and follow existing and modern pedagogical theories. In particular, the aim of designing educational scenarios is to reflect the latest research on the integration and utilization of serious games in the teaching of History and through distance learning. Furthermore, the activities aim at highlighting the role of ICT in teaching strategies, which support the playful way of approaching knowledge, with particular emphasis on supporting and promoting transitions from frontal teaching, group teaching and in collaborative learning, transforming the form of teaching from teacher-centered to student-centered, by deploying specific educational scenarios. The structure of the scenarios, their supported activities and the evaluation process, are closely intertwined with the plot of the digital educational serious game "BYRON", as well as the on-site project "MON REPO".
\end{abstract}

Keywords - Distance learning, Educational Scenarios, Game-centered learning, Co-operative learning.

\section{INTRODUCTION}

By the term "distance education" we envisage the type of education for students, who may not always be physically present at school. The latter found particular application within the educational community during the last two academic years due to the COVID-19 pandemic crisis. In principle, a distance learning program is either entirely remote or a combination of distance and traditional classroom teaching.

Furthermore, when we refer to asynchronous distance education, a remote platform is typically involved, in which the educational material is located, and students refer to it whenever they wish and within the environment they choose. In this form of education, students are able to (asynchronously) communicate and exchange their views

Submitted on November 4, 2021

Published on February 16, 2022.

K. Stamou, Department of History, Ionian University, Greece.

(e-mail: h18stam ${ }^{@}$ ionio.gr)

H. Koumentakou, Humanistic and Social Informatics Laboratory, Ionian University, Greece.

(e-mail: koumendakou ${ }^{\circledR}$ yahoo.gr)

Y. Voutos, Department of Informatics, Ionian University, Greece.

(e-mail: c16vout ${ }^{@}$ ionio.gr)

$\mathrm{Ph}$. Mylonas, Department of Informatics, Ionian University, Greece.

(e-mail: fmylonas@ionio.gr). with their classmates or with the teacher. On the other hand, synchronous distance learning considers the possibility of training in real time, often with visual contact. In this way, the teacher and the students have direct contact and unlimited possibilities of learning and direct communication.

During the recent curfew period due to the COVID-19 pandemic, a type of mixed distance learning was applied in many schools for the conduct of each lesson, which combined asynchronous (written) and modern (oral) online learning and which did not include any form of live communication. The combination of asynchronous and modern learning in an online environment has a significant advantage. In particular, oral communication offers a sense of immediacy, which is particularly effective for building social skills (such as mutual trust, open communication and group cohesion) and in cultivating students' perceptual ability [1], [2]. This verbal immediacy has a positive effect within an online environment when introducing a new topic, as it helps students to focus on educational activities and the perceptive ability that may be developed during the learning process [3]. However, although it is widely accepted that any type of distance learning (modern, asynchronous or even mixed) is not able to fully replace direct, face-to-face interaction, after the recent experience of the pandemic the educational community has managed transformed it into a very useful and supportive teaching tool.

The rest of the paper consists of six sections, starting with the presentation of the educator's perspective (II). Eventually, the third section (III) presents the reasoning about the scenarios that characterize the game. Moreover, within the next couple of sections the involvement (IV) and feedback (0) from students and teachers into the teaching practice are discussed. In the intermediate fifth section indicative activities that assist educators in teaching (V) are also presented. Finally, in the last section (VII), an evaluation of the results of the application of the educational scenarios in the game is included. 


\section{TEACHER'S PERSPECTIVE}

From the teachers' point of view, the widespread use of distance learning in secondary schools, even due to an unexpected event like a pandemic, formed an ideal opportunity for structural changes in the teaching practice. These kinds of changes are related to the development of teachers' digital skills, the pedagogical use of educational technology and the novel online evaluation methodologies according to existing pedagogical practices. Furthermore, they aim to apply alternative learning methods through the application of innovative pedagogical practices, such as the integration of a digital educational game into the actual classroom.

In particular, the proposed educational serious game, under the title "Experiential educational game for exploring the social identity of the revolution - BYRON" [4], aims to provoke and encourage the active participation of each student within the learning process of distance learning, while developing his self-efficacy. The game, through creating a challenging environment, directly sets goals for the students that are encouraged to achieve by participating into the various discrete and challenging game missions.

In fact, nowadays students are considered to be familiar with digital media and are able to interact comfortably within the environment of digital gaming and distance learning practices. In this context, the integration of such a digital game will develop the student's cognitive skills remotely in combination with the customizable educational scenarios and the proposed educational activities.

\section{EDUCATIONAL SCENARIOS}

In recent years the design of educational scenarios, related to teaching pre-selected cognitive modules, has been gradually developed and integrated into the teaching practice. An educational scenario is a teaching activity consisted of cognitive modules, focus oriented subject, and specific educational objectives, teaching principles and practices. Furthermore, educational scenarios are seen as a powerful educational tool for designing and organizing the curriculum in order to master the subject matter and, on the other hand, as an important aid for solving specific teaching issues that arise during the learning process [5]. According to Misfeldt [6], scenario-based education is a novel approach in understanding the organization of teaching, as these scenarios are related to in-person or virtual teaching conditions used to create the communicative state that attempts to immerse students in the given educational conditions presented by the educator.

It is clear that deploying ICT tools into the teaching practice befits the recent demands set by the educational community for implementing novel teaching methods, such as collaborative teaching. Furthermore, the new conditions that challenge educators (i.e., distance learning) have been strongly determined by the pandemic of COVID-19. It is noteworthy that implementing a scenario into a class environment is extremely time consuming, mainly due to a series of necessary educational activities that need to be integrated either in a simple or a more complex form in the process. Specifically, an educational activity is a state designed by the teacher that helps the student to achieve a learning objective. An educational activity usually involves one or more tasks to be completed that serve a specific objective [7]. Therefore, students are able to solve original and diligently structured tasks and puzzles by enriching the learning process with targeted educational activities based on utilizing scenarios [8].

A typical structure of an educational scenario is distinguished by its various characteristics, such as the identity of each scenario, its implementation framework, the teaching process, and its actual implementation in the classroom [9]. In terms of teaching methodology, the educational scenarios should promote the development of educators' competences and skills towards building a critical attitude on the use of ICT, which consequently leads to the much desired critical digital literacy.

In this framework, the "BYRON" serious game is based on an interdisciplinary process that bridges two quite distinct disciplines, namely Computer Science and History, by combining the expressiveness of creative writing and the interactivity of ICT tools and methods. Therefore, it inspires students to approach the historical period of the Greek Revolution in an alternative way, through gamification. Furthermore, the "MON REPO" project approach [10] incorporates the educational scenarios into a real-life open space paradigm, allowing for a novel teaching approach based heavily on gamification and participatory engagement of students in the process.

On the other hand, groups of students work enthusiastically in attractive collaborative and creative environments and the role teachers is advisory and supervisory at all stages of production. Furthermore, students nurture positive interdependence, individual and collective responsibility, mutual encouragement and facilitation of efforts to promote the group goal (i.e., immersion to the historic narrative). In particular, they practice social functional skills, such as expressing their opinions freely, and social cooperative skills, such as communication, building mutual trust and managing disagreements and conflicts [11].

The structure of the herein presented educational scenarios follows the design of the "BYRON" digital game, as well as the basic principles set out within the "MON REPO" project Firstly, four (4) training scenarios have been designed for each of the according four (4) missions of the serious game. Each educational scenario is directly related to the plot of each mission and offers the prospect to the student to make the most of the digital educational environment when he is called to do so. Secondly, it offers the teacher the opportunity to adjust his educational activities, according to the characteristics of the classroom and the particularities of his students.

In this context, the teacher can creatively exploit these educational tools, along with the challenges of each mission has to offer to the "classroom". Furthermore, for each level within the missions there are the respective educational activities, which are end up being enhanced via state-of-the art tools the ICT has to offer [12], [13]. It becomes clear that the specific educational scenarios are in line with the new educational orientation for the implementation of didactic proposals, which enhance the effective integration and utilization of ICT in the learning process [12]. 
On the other hand, the use of new technologies as teaching aids goes accordingly with the modern requirements of the educational community that aid the application of novel teaching methods, such as co-operative learning [13]. At the same time, the scenarios developed move in the direction of a "dialectic" with the digital educational game principles building a two-way relationship with it - while they are the basis for fruitful animation during the phase of reflection.

In particular, the implementation of introductory activities by the students under the guidance of the teacher can be planned before the students engage in the game and continue

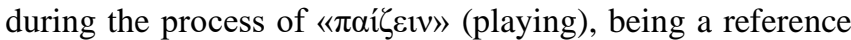
point in terms of understanding historical context of each game's mission. Furthermore, presenting the second introductory activity, it is pointed out that focuses on the effort to get to know the personality and action of the Power Carriers, who undertook the organization of the Greek Revolution and are the main characters in the first military confrontations with the enemy.

Under this notion we propose a framework for assisting teaching history in middle school, in order to incorporate a serious digital game into the process of distance learning [12]. It is worth mentioning that games, and in fact digital games, have characteristics with which modern students - who are characterized as "digital natives" or "digital learners" - are familiar with online tools such as immersion, action-based learning, instant feedback, action, and active participation.

\section{STUDENT ACTIVITIES}

Educators are capable of integrating digital serious gaming into the educational process through the appropriate means of technology. This allows the teacher to create a complex narrative, which shall be structured into educational scenarios, both during the preparation of the students and during the process of "playing", but also in the final phase of critical reflection, as well as to finally form an appealing, alternative learning environment. Under this context, the student has to take part into a series of specific learning activities, related to the game's theme (i.e.: The Greek Revolution), and one of those is the "Acquaintance with Power Carriers and role description".

Based on the suggested sources, 64 students at a middle school located in Athens, Greece were engaged with a preliminary version of the "BYRON" serious game over a period of several weeks during the 2020/21 academic year and searched for information about the individual armed or unarmed forces of the Greek Revolution and their contribution to its actual preparation and organization. Afterwards, they were called to record vocally this information in the form of words/phrases, or thematic sentences, by filling in the corresponding role indexing tabs (Table I).

The Blabberize platform [13], along with data derived from the above tabular descriptions regarding the Power Carriers of the Greek Revolution, allowed students to impersonate these roles as if they were in their own shoes. Particularly, we provide an illustrative example (Fig. 1), as a result of the pilot implementation of the program by the aforementioned students based on the well-known collaborative method.
TABLE I: ACQUAINTANCE WITH POWER CARRIERS AND ROLE DESCRIPTION, INDEXING TAB

\begin{tabular}{cl}
\hline \hline Power Carriers & $\ldots$ \\
\hline Character name & $\ldots$ \\
Typical clothing and equipment & $\ldots$ \\
Duties & $\ldots$ \\
Influence and connections & $\ldots$ \\
Action & $\ldots$ \\
Indicative historical figures & $\ldots$ \\
\hline \hline
\end{tabular}

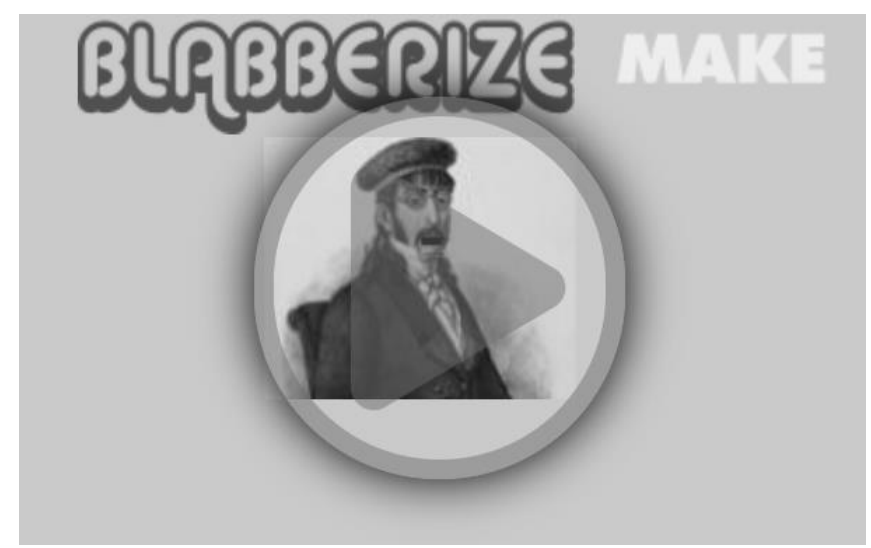

Fig. 1. An image excerpt from the Blabberize platform (source: [15]).

\section{InDICATIVE EDUCATIONAL ACTIVITIES}

As part of students' preparation for their introduction to the digital game, we prepared a series of educational activities. Each one reflects a historical narrative in which the student is asked to create an index of historical facts on a worksheet (Tables II and III). This section presents two of the thematic periods that the "BYRON" game focuses on, presented in the following.

\section{A. Beginning of the Greek Revolution and First Military Successes: Valtetsi-Tripolitsa-Dervenakia}

Following this didactic proposal students are called to understand the way of organization and preparation of the Greek revolutionaries, but also how they were led to the outbreak of the Greek Revolution. Also, through the first military successes, such as the battle of Valtetsi, the siege of Tripoli and the preparation of the battle of Dervenakia, they are called to recognize the actions of the power carriers, to understand and evaluate their actions and choices regarding the alliances, as well as the onset of attacks that took place.

TABLE II: WORKSHEET EXAMPLE

\begin{tabular}{|c|c|}
\hline Thematic Unit & The siege of Tripoli. \\
\hline Reflection & $\begin{array}{l}\text { The planning and preparation for the siege of } \\
\text { Tripoli. The warring parties and their actions }\end{array}$ \\
\hline Suggested activity & Record the conflicting parties \\
\hline
\end{tabular}

Based on the historical knowledge and suggested historical sources throughout the game, students are asked to formulate a concept map, utilizing the Creately application [16], record the conflicting parties, the protagonists, their decisions, and strategy, highlighting the flow of events in the process. An illustrative example/creation of students during the pilot implementation of the program through the collaborative method of student enablement is depicted (Fig. 2). 


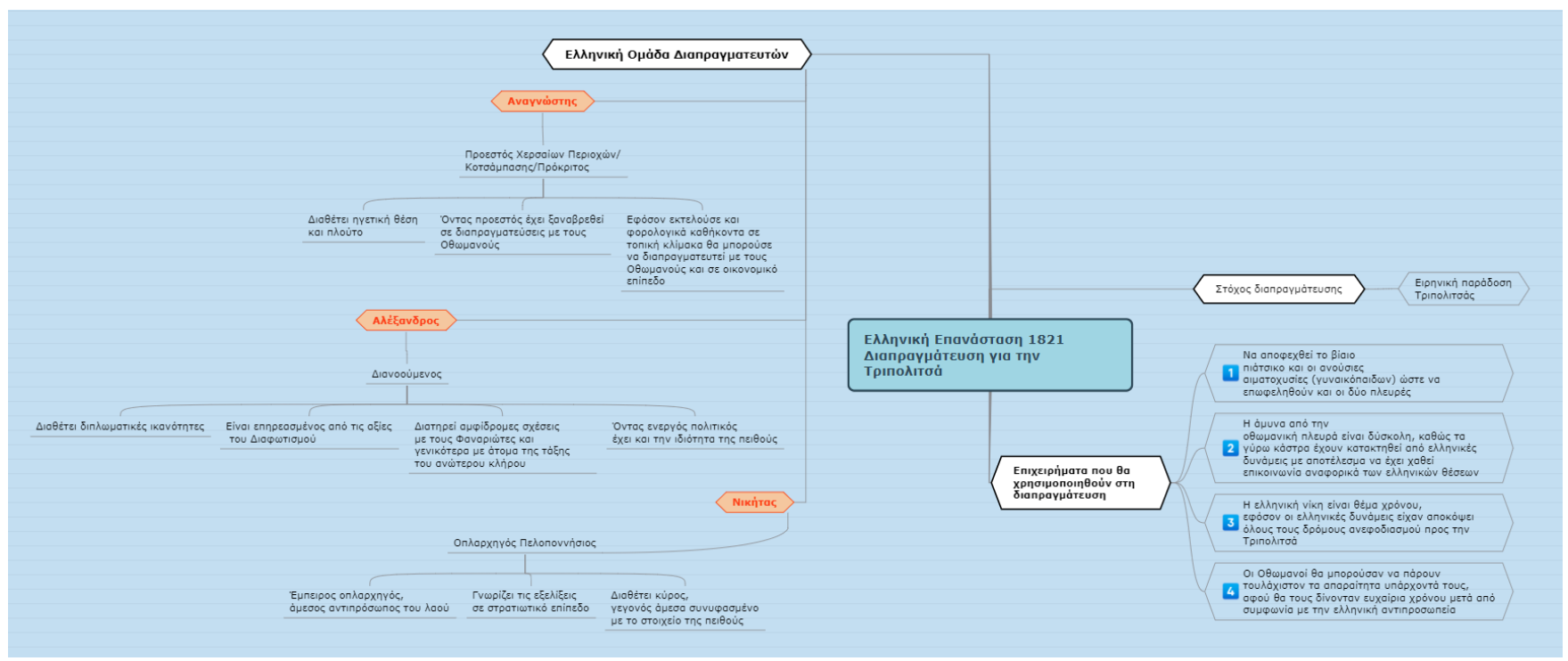

Fig. 2. Tripoli's siege involving parties illustrated through the mindomo platform (source:[17]).

B. Messolonghi during the Struggle. The Role and Contribution of the Philhellenes \& the Exodus of Messolonghi

Following this didactic proposal students are called to understand the movement of Philhellenism, the importance of the Press and the dissemination of ideas in the Public Sphere, as well as to prepare for the Exodus of the Messolonghi.

This section aims to acquaint the students with the mechanism of organization and structure of a newspaper and at the same time through the publication of a newspaper, to realize the role of the Press at that time, but also of the persons behind the actual spread of information. In particularly, they are called to understand that the publications during the Struggle were not only a means of information, but also its guiding instruments.

TABLE III: WORKSHEET EXAMPLE

\begin{tabular}{ll}
\hline \hline Thematic Unit & Exodus of the Messolonghi and Philhellenism. \\
\hline Thematic Unit & The role of the Press at the time of the Struggle. \\
Reflection & Publication of a Newspaper \\
\hline \hline
\end{tabular}

After being divided into two action groups, students have to study the proposed issues per group by employing the Padlet platform [18], as well as to note down the main topics mentioned in each issue (per essay, article, etc.) by thematic periods and in the order in which they are presented.

\section{Evaluation PROCESS}

It is rather true that the COVID-19 pandemic disrupted the evaluation process that was initially scheduled. Due to the non-attendance of courses in person, the projects' team acquire $\delta$ the necessary feedback in two phases. The first phase aided developers to optimize the educational aim of the game, thus allowing teachers to qualitatively evaluate the game in both phases, before and after the completion of the actual game development. More specifically, during both phases students and teachers will fill-in the evaluation questionnaires in the form of a satisfactory rate [19], [20]. It is stressed that emojis are used as a form of satisfaction and/or positive response of the respondent in relation to a specific question. This simplifies the whole process and can give a general impression of the game. Furthermore, the game itself is a process of self-evaluation, as the player's development in the game depends on the degree of immersion in the historical context.

To illustrate the process that is taking place during the first evaluation phase, once the training scenario's design phase is completed, it is implemented into the course, either in person or remotely. While collaborating with the students, the teacher integrates the game into the course of the lesson; she/he is then able to develop an important tool for understanding and carrying out each task related to the game's educational scenarios. During the evaluation phase, the teacher and the students are asked to fill in respective questionnaires that refer to one or more levels/missions of the game and assess the quality of the scenarios, based on the given historical background of each level/mission.

The purpose of evaluating the levels/missions of the game in an on-the-go manner within the first phase, as well as the accompanying educational scenarios of the game through the respective questionnaires, is to provide the research team detailed feedback from teachers and students from the application of the educational scenarios in real-life teaching conditions. As a result, the acquired answers were given during the initial deployment of the game in order to evaluate the view of the content related to the discussions and the data left while playing the game for the first time.

In this way the project team is able to investigate any problems that arose during the game's development, to come up with further improvements to the content in the game, as the modification of key problems is a key prerequisite on the game development. Undoubtedly, evaluation, as a decisionmaking process, is essential to support restructuring and improvement on the scenarios, contributing to effective learning and providing better learning outcomes.

The first assessment phase of the game was carried out in 4 schools. The questionnaires were divided into 2 categories and were answered by 153 students and 14 teachers. Although this sample is not considered adequate for a specific type of quantitative analysis, it is considered adequate for a qualitative analysis of the results, considering also the difficult conditions that the educational community had to face due to the COVID-19 pandemic crisis. Consequently, the 
research team managed to conduct qualitative assessment from the completed questionnaires, resulting into a satisfactory insight on the organization of the digital game and the design of the educational scenarios.

In particular, the students' opinion regarding the educational scenarios for the first two missions, seems to indicate positively the scenario's originality, the variety of historical context and their combination with literary genres and texts. These were evaluated as an excellent learning aid in relation to the power players of the Greek Revolution, the historical events and the strategic decisions made by the historic characters of the game, as well as political processes such as voting (Fig. 3-6).

The accompanying texts of the power carriers are helpful for the correct choice of character in the first mission.

153 responses

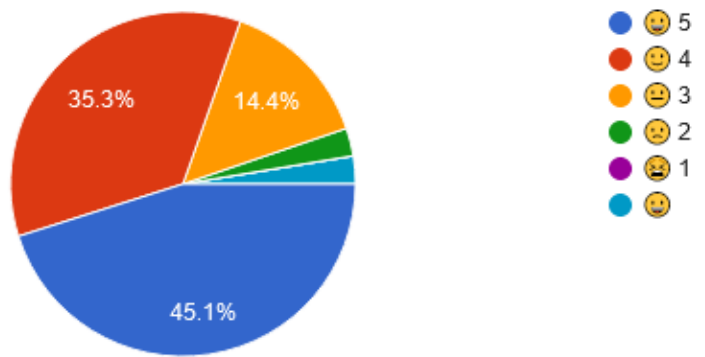

Fig. 3. The results on the satisfaction rate for the supporting texts in relation to the power carriers.

The introductory texts of the 2 nd mission provide the necessary information to meet the challenge of the mission/ track.

153 responses

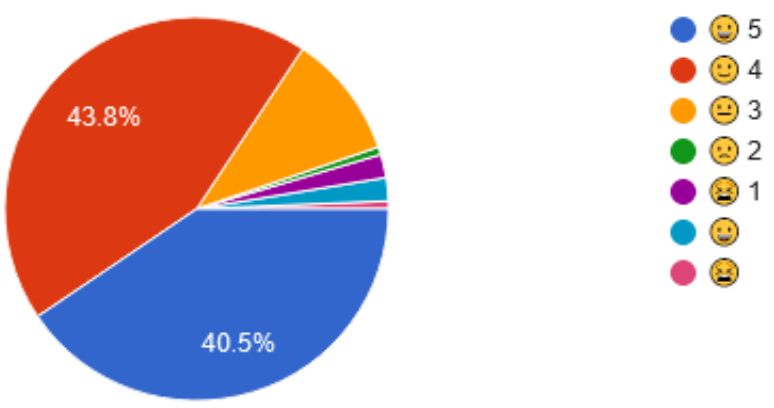

Fig. 4. The results on the adequacy of the accompanying material for the implementation of the 2 nd mission

The descriptive texts helped me choose the right characters.

153 responses

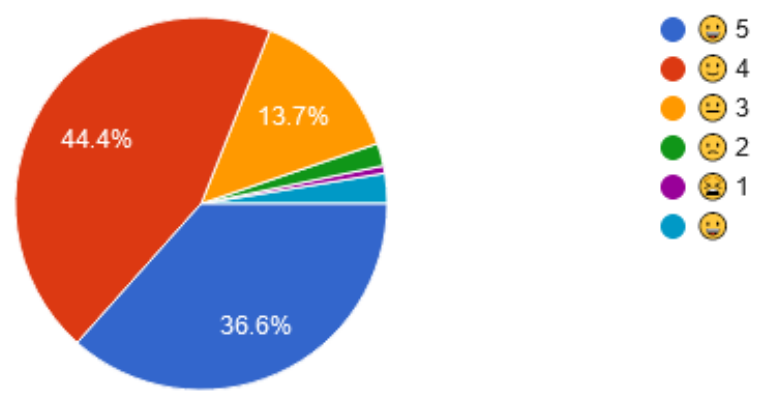

Fig. 5. The effect of descriptive texts on choosing the correct game characters.
I understood the importance of voting in Parliament.

153 responses

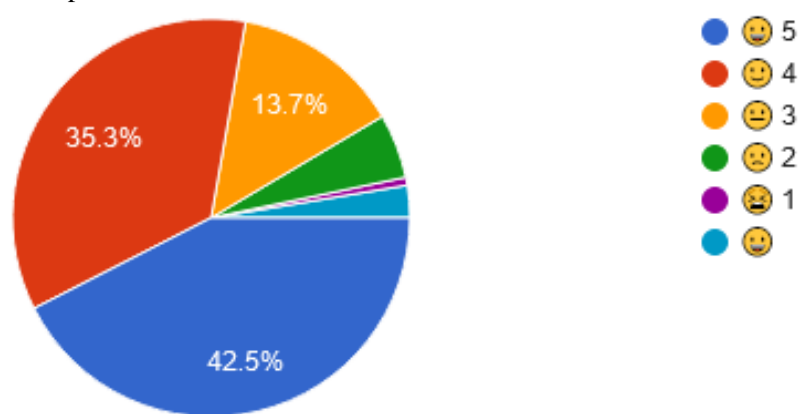

Fig. 6. Students' understanding of the events in parliament.

The results indicate that the systematic effort to integrate multimedia in the game is popular among students (Fig. 7 and 8).

The use of the following multimedia is sufficient in the game

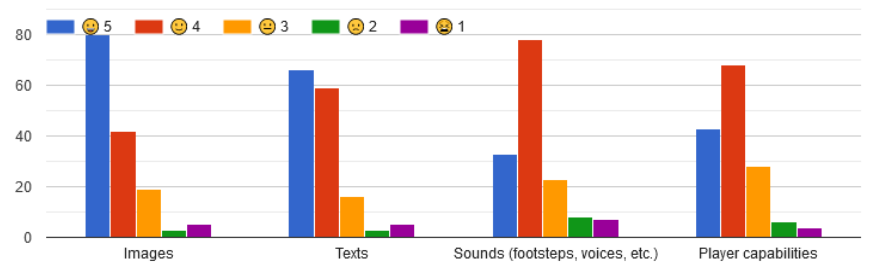

Fig. 7. The adequacy of multimedia in the game.

Playing the game aroused my interest more

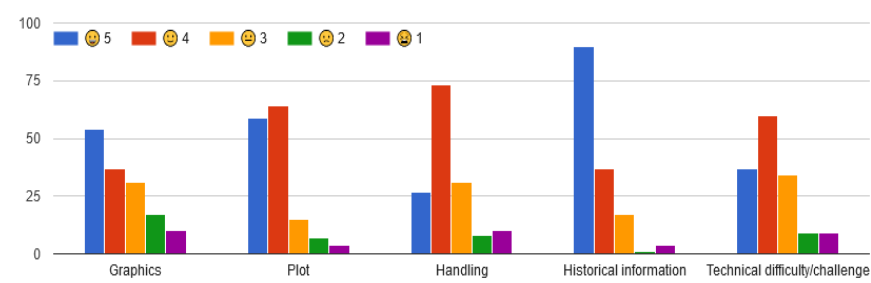

Fig. 8. Challenge of interest to players).

Also, from the teachers' point of view, the systematic involvement of students in the teaching practice is observed, which promotes the student's self-activity and initiative (Fig. 9-11).

The $1^{\text {st }} \& 2^{\text {nd }}$ mission contain many elements of creativity that cause the player's pleasure.

\section{4 responses}

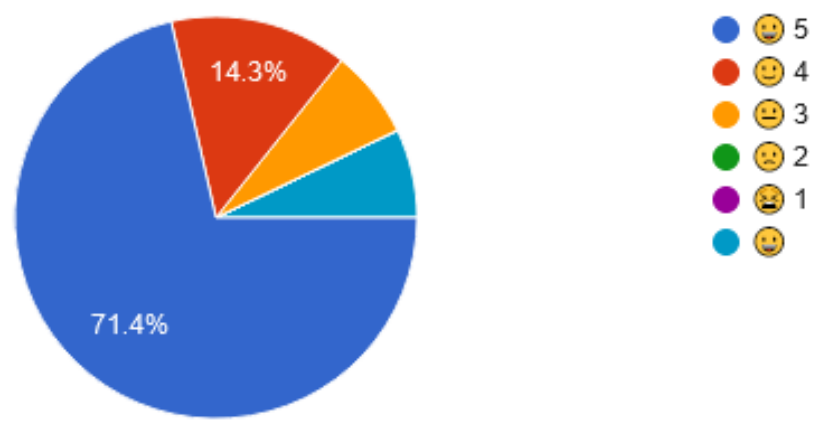

Fig. 9. Creativity elements in the game. 
The $1^{\text {st }} \& 2^{\text {nd }}$ mission are well organized, as they follow the given historical context logically and there is very good coherence.

14 responses

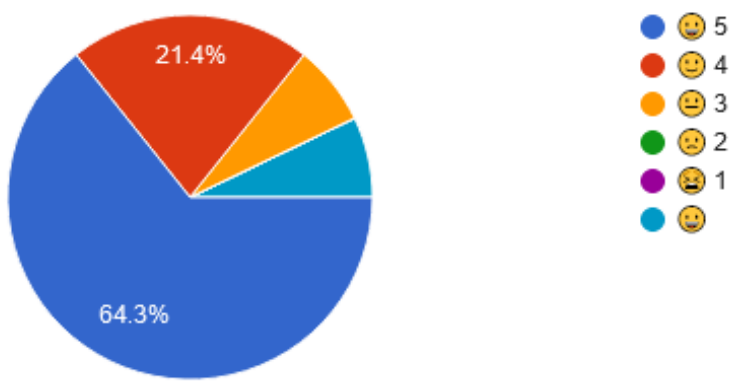

Fig. 10. Adequacy of the historical context in the first two missions of the "BYRON" game.

The suggested activities of the educational scenarios of the $1^{\text {st }} \& 2^{\text {nd }}$ mission make the involvement of the student-player in the historical content successful and multilevel.

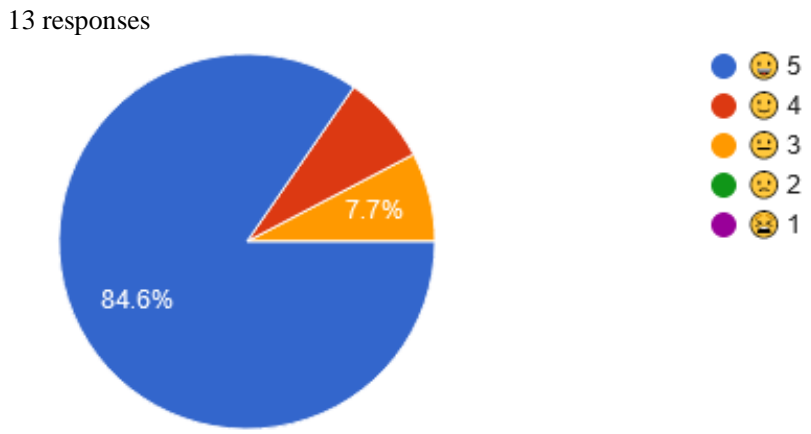

Fig. 11. Teachers' perspective on the impact of scenarios on students' involvement in the historical context.

The results of the data collected from the student and teacher questionnaires regarding the design of the game and the accompanying educational scenarios indicate that the educational scenarios helped significantly in the planning of teaching, as a result of the creative and multilevel reform of the learning process. More specifically, it is shown that the proposed scenarios helped:

- making decisions on teaching methods, tools and means of teaching,

- offering the teacher the opportunity to take initiatives,

- highlighting his/her scientific training,

- strengthening his/her pedagogical skills,

- resulting in the stimulation of students' interest and

- building of a meaningful pedagogical relationship in class environment (virtual or real-life).

It is worth mentioning that a second deployment of the game will follow, and subsequent improvements will take place during the final phase of the projects. In particular, the game and training scenarios will be reviewed for a second time to examine the changes made since the first review phase. The second deployment will be repeated again in selected schools in Corfu, Greece and Athens, Greece. The research team will also repeat the same evaluation process by filling student and teacher questionnaires, conducting reflective discussions after the game and monitoring their evolvement from the game's learning analytics. Also, will be verified whether the initial observations of teachers and students as reflected in the questionnaires during the first test of the game's operation have been carried out and whether, in their opinion, further modifications to certain details of the game are needed.

\section{CONCLUSIONS}

Distance Learning has the potential to offer an open system that combines access to information and targeted communication in a dynamic and spiritually active learning community. Also, the possibility of applying collaborative learning methods remotely, which provide opportunities for multilevel and meaningful learning experiences, while providing the teacher the opportunity to design and implement targeted educational actions, such as educational scenarios enriched with digital tools.

The educational scenarios, based on a digital educational game and real-life on-site open space approaches, support and promote the transition from frontal teaching to collaborative learning, from lecture to exploratory method. They employ ICT as educational scenarios, fostering problem-solving, developing critical thinking and decision-making skills, and leading teachers and students to critical digital literacy. In distance learning, the role of the teacher remains mediating, as he / she has the responsibility of the didactic implementation of the educational scenario but also the possibility of its transformation, whenever it is considered necessary.

Furthermore, through the gamification aspect we propose a process of self-evaluation, as the player's development, especially in the "BYRON" game, depends on the degree of immersion on the historical or other context. Also, its evaluation by the students and teachers themselves, as dynamic actors of the historical context presented through the game, it provides prospects for further development of the application of the game in the classroom environment (physical or virtual).

In conclusion, through the integration of digital educational scenarios in distance learning, we believe that the systematic involvement of students in the teaching practice is achieved, as it promotes self-action and enablement of initiative on behalf of the students. In addition, the teacher is offered the opportunity to take initiatives, highlighting his scientific training, strengthening his pedagogical skills, and finally animating the interest of students while building a meaningful pedagogical relationship with them, as a result of the creative and multilevel process of student reform.

\section{REFERENCES}

[1] Baker J. D. An investigation of relationships among instructor immediacy and affective and cognitive learning in the online classroom. The Internet and Higher Education, 2004;7(1):1-13.

[2] Swan K., \& Richardson J. C. Examining social presence in online courses in relation to students' perceived learning and satisfaction. Journal of Asynchronous Learning Networks, 2003;7: 68-82.

[3] Garrison, Randy D. E-Learning in the 21st Century. A Community of Inquiry Framework for Research and Practice. Routledge, 2016.

[4] Experiential educational game for exploring the social identity of the revolution - BYRON. Available: https://hilab.di.ionio.gr/byron/.

[5] Tetchueng J., Garlatti1 S., \& Laube S. A context-aware learning system based on generic scenarios and the theory in didactic anthropology of knowledge. International Journal of Computer \& Applications, 2008;5(1):71-87. 
[6] Misfeldt M. Scenario based education as a framework for understanding students engagement and learning in a project management simulation game. The Electronic Journal of e-Learning, 2015:13(3):181-191.

[7] Khaldi M., Barhone J., Erradi M. and Khaldi M. The educational scenario architecture of a learning situation. Global Journal of Engineering and Technology Advances, 2020;3(1):27-40.

[8] Clark R. Accelerating expertise with scenario based learning. Learning blueprint. Merrifield, VA: American Society for Teaching and Development, 2009.

[9] Fragaki M. Creating an E-Learning Community for the pedagogical use of Information and Communication Technologies in educational practice. Doctoral thesis. National and Kapodistrian University of Athens, Field of Mathematics and Informatics, Pedagogical Department of Primary Education, 2008.

[10] Strengthening User Experience \& Cultural Innovation through Experiential Knowledge Enhancement with Enhanced Reality Technologies. Available: https://monrepo.online/.

[11] Hadjidimou D. Major Training Programme - Basic training material: volume A': general part. Initial Publication May 2011

[12] Koutromanos G., Pittara T., \& Tripoulas C. "Clavis Aurea": An augmented Reality Game for the Teaching of Local History. European Journal of Engineering and Technology Research, 2020.

[13] Angelopoulos P. \& Solomou E. The Shield of Achilles using 3D Technologies to Support Teaching Scenarios of Homeric Epics. European Journal of Engineering and Technology Research, 2020:22 25.

[14] labberize.com - Got A picture? Blabberize it! Available: https://blabberize.com.

[15] A $\lambda \dot{\varepsilon} \xi \alpha v \delta \rho \circ \varsigma$ - BYP $\Omega N 1821$ - Blabberize it! Available: https://blabberize.com/view/id/2022874.

[16] Chart, Diagram \& Visual Workspace Software | Crately. Available: https://creately.com.

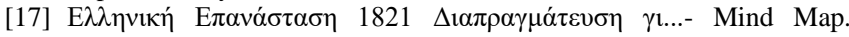
Available: https://www.mindomo.com/mindmap/-18211d0790a7380d44d6bf0e37a4faa620f1.

[18] Padlet Dashboard. Available: https://padlet.com/dashboard.

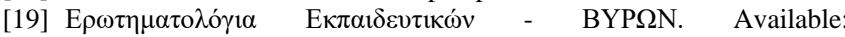
https://forms.gle/rbdLUFn6bcfZogYy6/.

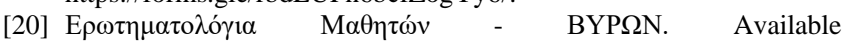
https://forms.gle/PoC5cX6AbZnc2N9i7/.

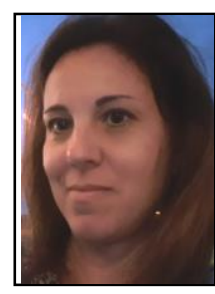

Klio Stamou is a graduate of the National \& Kapodistrian University of Athens (UoA), School of Philosophy, Department of Philology, specializing in Linguistics, (2001), while she holds a Master's Degree from UoA in the Interdepartmental Program of "Teaching of Modern Greek Language as a second or foreign language", (2005).

Since 2018 she is preparing her Doctoral Thesis at the Department of History, Ionian University, in the field of learning environments with the application of the theory and methods of collaborative learning. Since 2005 she has been working at the German School of Athens, while she has rich experience in teaching courses, in organizing international student and professional conferences. She has worked in the development, technical management and documentation of a number of European and National Research \& Development Programs, while she has been included in the Register of Experts of the Pedagogical Institute. Her professional and research interests focus on the elaboration of linguistic features of modern speech, the repositories of digital objects and their representation, the design and development of educational activities, the semantic analysis of textual contents and participation in related scientific and technical activities.

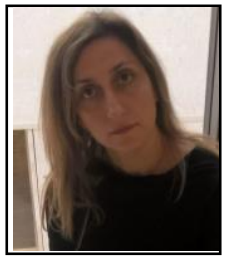

Helena Koumentakou is a graduate of the National \& Kapodistrian University of Athens (UoA), School of Philosophy, Department of History and Archaeology, specializing in History, (1997)

Since 2018 she is preparing her Master's Degree from Hellenic Open University in the Interdepartmental Program in the field of Creative Writing. Since 2006 she has been working at the German School of Athens, while she has rich experience in teaching courses, in organizing debate conferences and competitions concerning the Oral History \& Memory.

She has worked in the development and documentation of a number of European and National Research \& Development Programs. Her professional and research interests focus on the elaboration of creative writing in modern teaching methods, the design and development of educational activities, the semantic analysis of textual contents and participation in related scientific and technical activities.

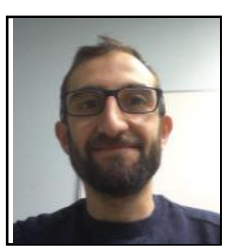

Yorghos Voutos was born in London, UK in 1985. He is a graduate of the Technological Educational Institute of the Ionian Islands, Department of Environmental Technology. He holds a Master's degree in the field of Geoinformatics from Harokopio University. Also, he is a $\mathrm{PhD}$ Candidate at the Department of Informatics of the Ionian University in the subject of Geo-spatial semantics. He has many years of professional experience in research projects in the field of environmental, cultural and educational studies. His research work has been published and presented through papers (collective and individual) in reputable International and Greek scientific journals and conferences. He has many years of involvement with civil society in voluntary activities and active participation in NGOs in the fields of culture and environment. Furthermore, has experience in alternative tourism and in his free time he is involved in outdoor activities.

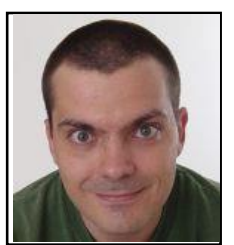

Phivos Mylonas was born in Athens in 1978. He received his Diploma in Electrical and Computer Engineering from the National Technical University of Athens (NTUA) in 2001, his Master of Science (M.Sc.) in Advanced Information Systems from the National \& Kapodestrian University of Athens (UoA) in 2003 and earned his $\mathrm{Ph} . \mathrm{D}$. degree (with distinction) at the former University (NTUA) in 2008. He is currently a tenured Associate Professor by the Department of Informatics of the Ionian University, Greece and collaborates as a Senior Researcher with the Intelligent Systems, Content, and Interaction Laboratory, School of Electrical and Computer Engineering, Department of Computer Science of the National Technical University of Athens, Greece.

His research interests include content-based information retrieval, visual context representation and analysis, knowledge-assisted multimedia analysis, issues related to multimedia personalization, user adaptation, user modeling and profiling. He has published articles in 43 international journals and 40 book chapters, he is the author of 126 papers in international conferences and workshops, he has edited 10 books and is a guest editor of 15 international journals, he is a reviewer for 55 international journals and has been actively involved in the organization of more than 150 international conferences and workshops.

$\mathrm{He}$ is a member of the Technical Chamber of Greece since 2001, a member of the Hellenic Association of Mechanical \& Electrical Engineers since 2002 and a member of W3C since 2009, whereas he is a past member of IEEE (1999-2010) and ACM (2001-2010) 